\title{
Public Health and Epidemiological Databases for the Enhancement of Medical Education
}

Qazi Mohammad Sajid Jamal ${ }^{1 *}$, Mughees Uddin Siddiqui ${ }^{1}$, Mohammad Abdulrahman Alzohairy ${ }^{2}$ and Mohammed Abdullah Al Karaawi

1. Department of Health Information Management, College of Applied Medical Sciences, Buraydah Colleges, Al-Qassim, Kingdom of Saudi Arabia.

2. Department of Clinical Laboratory, College of Applied Medical Sciences, Buraydah Colleges, Al-Qassim, Kingdom of Saudi Arabia.

\begin{abstract}
The collaboration of public health education and information technology has made patient care safer and more reliable than before. Nurses and doctors use handheld computers to record a patient's medical history and check that they are administering the correct treatment. Fortunately Public Health Informatics (PHI) is the intersecting point of technology and public health. Therefore, the inclusion of online medical and epidemiology databases in the course curriculum of budding medical professionals and postgraduate students would be beneficial in enhancing the quality of health care, extensive epidemiological research, health education, health policies, health planning and consumer satisfaction as well. The purpose of this article is to discuss and provide introduction of various databases which have huge information and it could be used to enhance the public health education.
\end{abstract}

Abbreviations: Information Technology, Public Health Informatics, Public Health Education, Databases Correspondence: sajqazi@gmail.com

DOI: 10.5210/ojphi.v7i2.5853

Copyright @2015 the author(s)

This is an Open Access article. Authors own copyright of their articles appearing in the Online Journal of Public Health Informatics. Readers may copy articles without permission of the copyright owner(s), as long as the author and OJPHI are acknowledged in the copy and the copy is used for educational, not-for-profit purposes

\section{Introduction}

Information technology can be an essential tool and important linkage for the current medical education. The article explores the need of information technology in the field of public health education to provide the best knowledge. As we know, through information technology, we can explore, transmit or retrieve the data as a useful resource of our interest. In the current era of modern technology, we can implement the health information technology in our current medical education systems. Major fields of health information technology are PHI, biomedical informatics, telemedicine, radio-informatics, pharmaco-informatics and bioinformatics. The fastest growing new era of biomedical informatics is building a splash in biomedical education, research and data management.

PHI is the systemic application of available online information and computer science to public health practice, research and planning. Therefore the PHI strategies would help the medical 
professionals have complete information related to disease management, treatment etc. The available epidemiology database would help epidemiologists, public health researchers, health managers, health policy makers, health educationist and health philanthropist as well in understanding the disease distribution, its determinants and indicators, morbidity, mortality statistics, disease trend,and its causing factors, aggravating factors and ways of prevention. PHI innovations have prepared a roadmap in improving health in the following ways:

- Tie up between the geographically dispersed health providers and consumers.

- Delivery of public-health services by strengthening and streamlining data collection.

- Utilization of electronic health records and improved laboratory systems to support primary and secondary prevention.

- Data collection of research studies such as drug and vaccine trials.

- Enhancing medication system informatics through evidence based, rational and cost effective prescribing.

- Monitoring chronic disease and ensuring that patients stick to their treatments.

Keeping in view the growing demand and benefits for the collaboration of public health related issues and information technology, it seems mandatory that the public health education during medical education must be well equipped with the latest databases in order to provide the best in class and updated medical knowledge to the budding medical professional. This inclusion would definitely help them to understand the urgency and necessity to gain sound knowledge of latest available medical databases in order to implement their knowledge at the district level and national level as well as serving the mankind devoid of latest medical facilities. In this fast and competitive world where the entire globe is online the latest update of medical databases can also help the medical professional to take quick and correct decision with minimal chances of error, and on the other hand it will also help the community to avail medical benefits at the consumers end.

In this era of technology, the information technology is playing a vital role in different spheres of human life. Human lives are benefitted with the emergence of information technology by making the use of online available information related to disease, its sign, symptoms, precautionary measures and available contact information of the experts those can provide assistance when needed. Furthermore, it has become very easy for the human beings to develop an understanding about their biological system, seasonal diseases their home based treatments and precautions, food and nutrition, etc. Many databases and online resources are freely available for the retrieval of the information has also enabled doctors to use e-mail, texts, videos, and conference facilities to consult colleagues from all over the world. This practice, known as telemedicine, is especially useful for doctors and patients in rural and underdeveloped areas. The emergence of robotic surgery, telemedicine, hospital information system, a centralized information system of the hospitals at the district level and state level as well demands the inclusion of biological and epidemiological databases in the medical course curriculum for the enhancement of public health education. But the major drawback is that it's not included in our education syllabus at the larger level. All the informatics resources have huge utilization at the academic level as well as research level. We can put the information about online biological and epidemiological databases in the syllabus which can definitely prove as strong asset in imparting public health education . 
The tools of public health informatics enable practitioners, researchers obtain a complete picture of the population's health and risk status and gather information from disparate resources. Online epidemiological databases can accurately predict medical trends.

Now we can decide our self why the biological and epidemiological databases should not be included in the medical course curriculum. Therefore, it is a need of an hour to fill the gap between the information technology and current public health education in order to utilize the online available resources at its best and serve the entire mankind.

\section{Databases for the Biomedical Information}

Currently huge biomedical information is available through different online resources worldwide. In this section we are going to discuss the major databases.

\section{PubMedHealth}

National Center for Biotechnology Information, US National Library of Medicine: 8600 Rockville Pike, Bethesda MD, 20894.

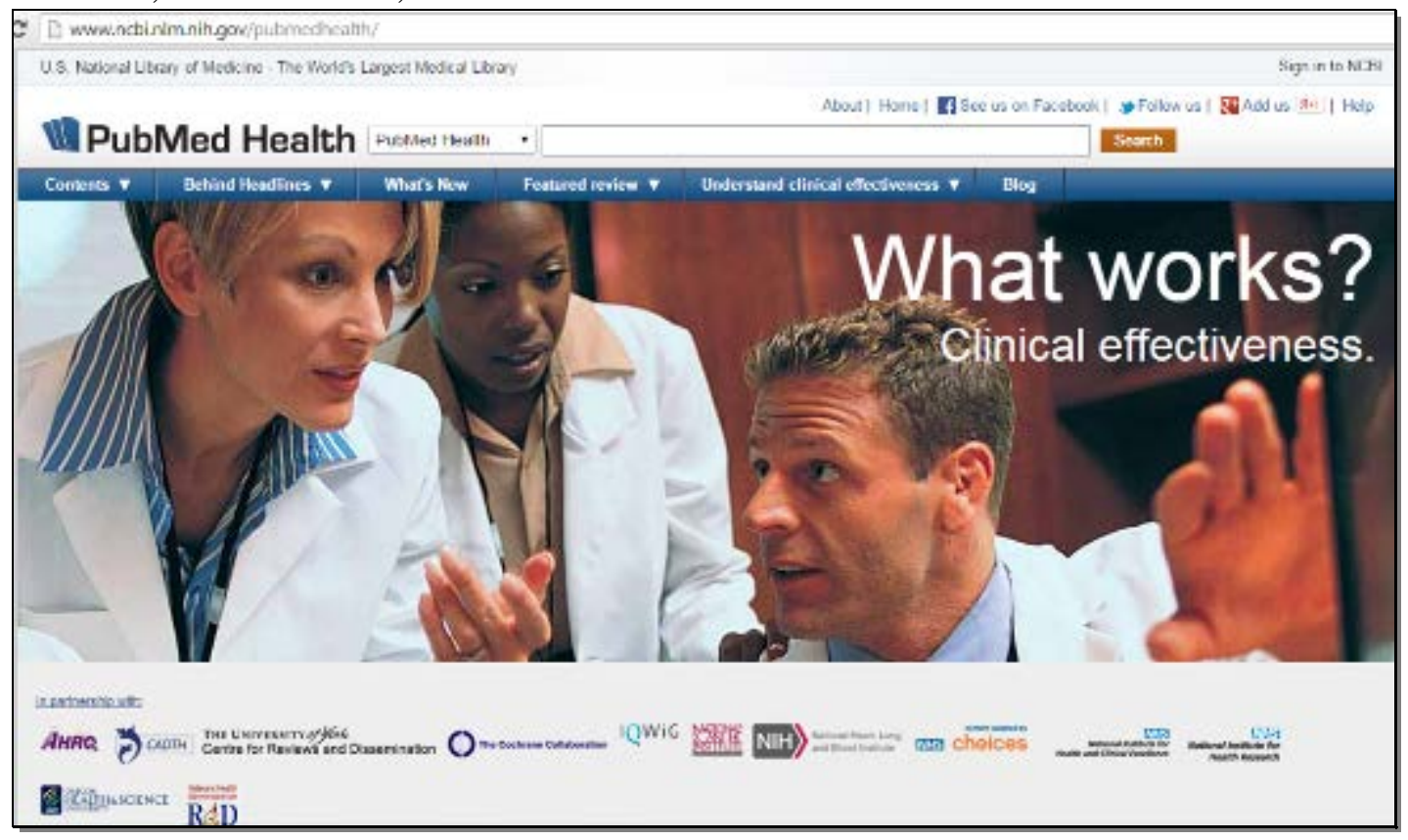

Figure 1: Home Page of PubMed Health

The emergence of PubMed Health in Google search engine has been a notable topic among medical librarians and the blogging community. In August 2010, the MidContinental Region News [1] announced the new PubMed Health resource from the National Center for Biotechnology Information (NCBI), which was quickly followed by a post from The Krafty Librarian [2]; however, no official announcement was made about this new resource. Then, PubMed Health appeared as the number one Google search result for medications starting in August 2010 and made a bigger appearance in February 2011 [3], creating several questions among the blogging community. With still no official announcement, the blogging community was left to fill in the gaps [4]. The sudden arrival of this new resource created a flurry of 
questions followed by uncertainty until finally NCBI tweeted [5] about the new PubMed Health on March 2, 2011, with a link to the newly released home page.

PubMed Health includes consumer guides summarizing comparative effectiveness research, fact sheets on diseases and conditions, information on drugs and supplements, encyclopedic overviews of health topics, and links to external websites [6]. The content on PubMed Health is supplied and updated by the following resources: "Comparative Effectiveness Review Summary Guides for Consumers" from the Agency for Healthcare Research and Quality (AHRQ); "InformedHealthOnline: Fact Sheets and Research Summaries" from the German Institute for Quality and Efficiency in Health Care (IQWiG); PubMed Clinical Q\&A, NCBI summaries of comparative effectiveness drug reports; A.D.A.M. Medical Encyclopedia; and American Society of Health-Systems Pharmacists consumer medication information [6]. Comparing the content and content sources to MedlinePlus reveals several similarities - even identical informationbetween the two resources.

Website: http://www.ncbi.nlm.nih.gov/pubmedhealth/

\section{The Visible Human Project ${ }^{\circledR}$}

The Visible Human Project ${ }^{\circledR}$ is an outgrowth of the NLM's 1986 Long-Range Plan. It is the creation of complete, anatomically detailed, three-dimensional representations of the normal male and female human bodies. Acquisition of transverse CT, MR and cryosection images of representative male and female cadavers has been completed. The male was sectioned at one millimeter intervals, the female at one-third of millimeter intervals.

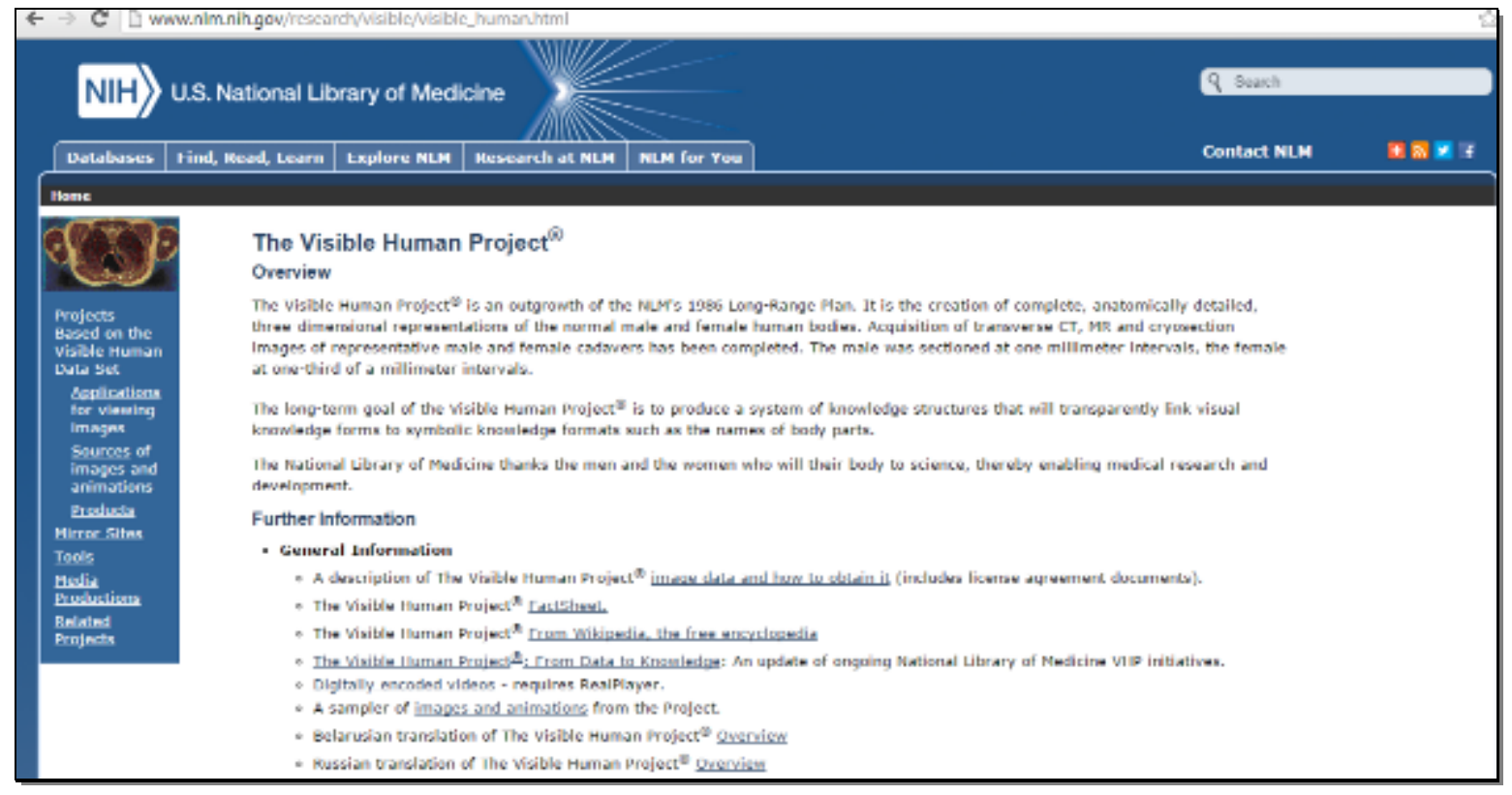

Figure 2: Home Page of the Visible Human Projects

The long-term goal of the Visible Human Project ${ }^{\circledR}$ is to produce a system of knowledge structures that will transparently link visual knowledge forms to symbolic knowledge formats such as the names of body parts [7]. 
Website: http://www.nlm.nih.gov/research/visible/visible_human.html

\section{Unified Medical Language System ${ }^{\circledR}\left(\right.$ UMLS $\left.^{\circledR}\right)$}

In order to enable interoperability between computer systems the UMLS, or Unified Medical Language System is a software that brings together numerous health and biomedical vocabularies .

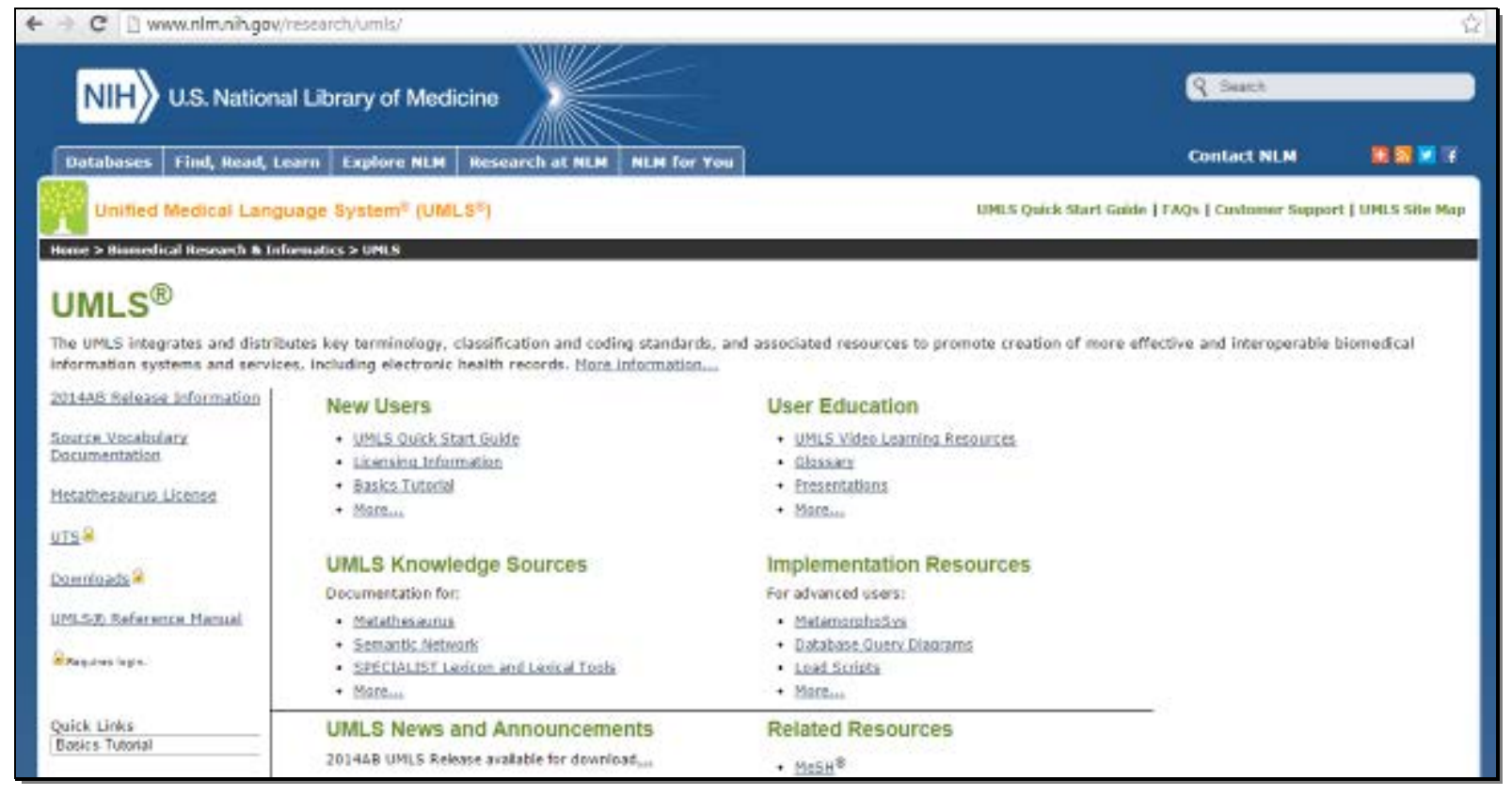

Figure 3: Home Page of UMLS

You can use the UMLS to enhance or develop applications, such as electronic health records, classification tools, dictionaries and language translators [8].

Website: http://www.nlm.nih.gov/research/umls/

\section{Web-based Medical Information Retrieval System (WebMIRS)}

The Web-based Medical Information Retrieval System. WebMIRS is a graphical Java program providing access to the NHANES II \& III databases of medical survey data and x-ray images [9]. 


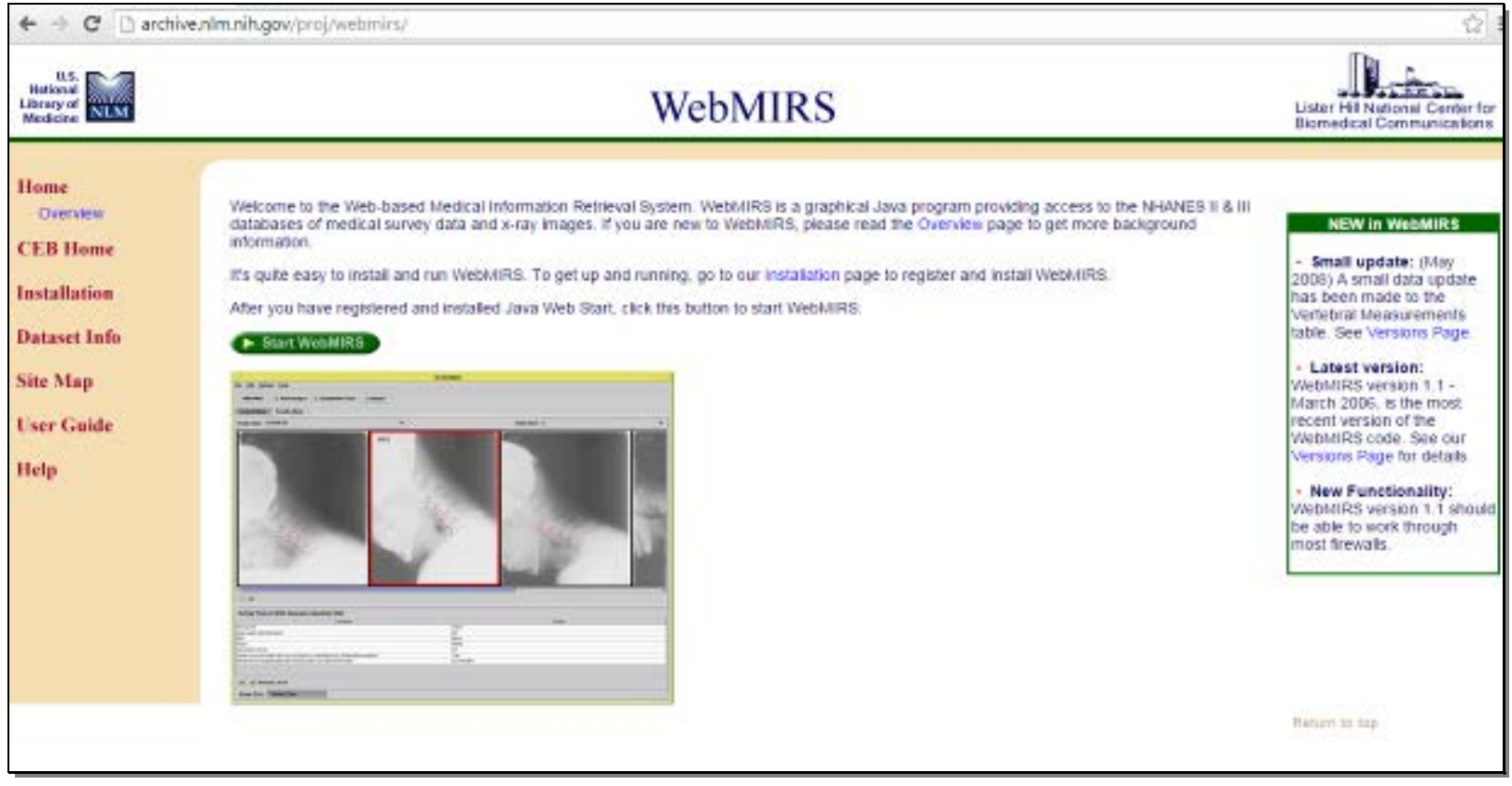

Figure 4: Home Page of WebMIRS

Website: http://archive.nlm.nih.gov/proj/webmirs/

\section{The A.D.A.M. Medical Encyclopedia}

The A.D.A.M. Medical Encyclopedia includes over 4,000 articles about diseases, tests, symptoms, injuries, and surgeries. It also contains an extensive library of medical photographs and illustrations [10].

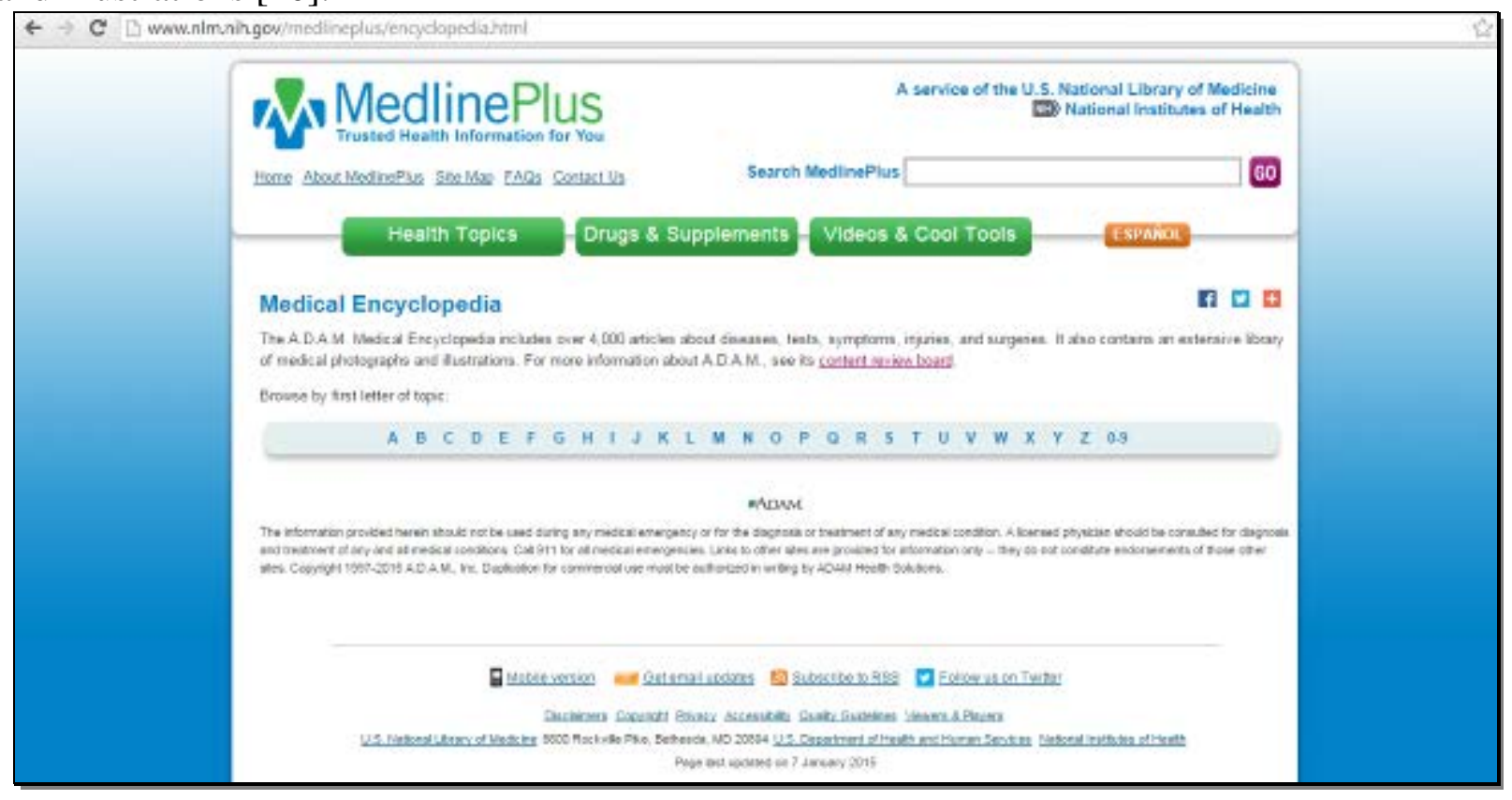

Figure 5: Home Page of ADAM Medical encyclopedia

Website: http://www.nlm.nih.gov/medlineplus/encyclopedia.html 


\section{The ALlele FREquency Database}

The purpose of designing ALFRED is to make allele frequency data on human population samples readily available for use by the scientific and educational communities.

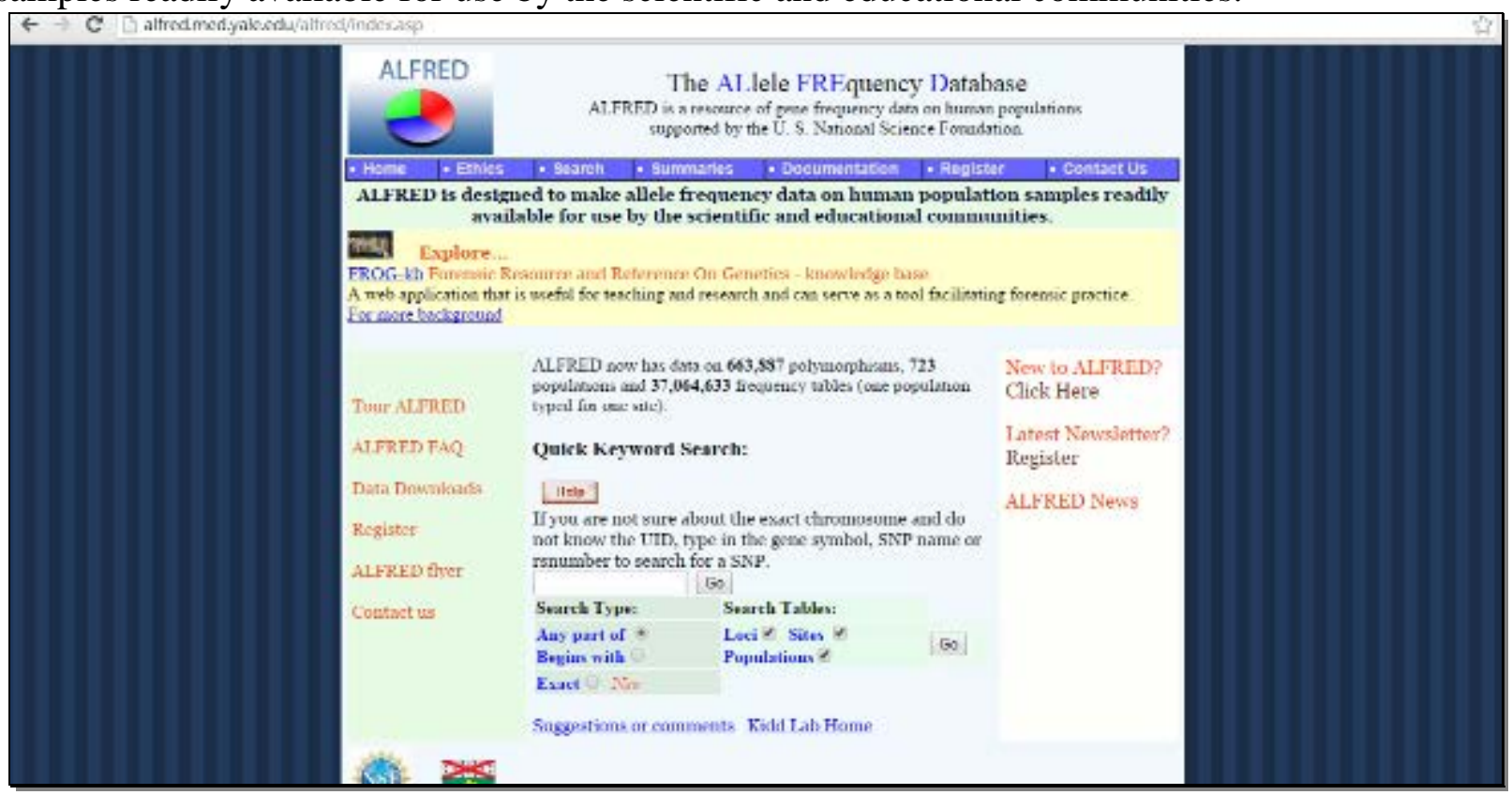

Figure 6: Home Page of ALFRED

The ALelle FREquency Database (ALFRED) is designed to store and disseminate frequencies of alleles at human autosomal polymorphic sites for multiple defined population samples, primarily for the population genetics and molecular anthropology communities. The focus is on allele frequencies of normal, common DNA variants, i.e., polymorphisms, in samples of anthropologically defined populations. Links are provided to molecular databases for precise definitions and locations of the polymorphisms and to anthropological databases for linguistic, ethnographic and demographic information on the populations sampled. References to publications are associated with the frequencies and linked to PubMed, whenever possible. Many polymorphisms have links to low-tech protocols suitable for small laboratories engaged in anthropological research. ALFRED has information on 672 polymorphic sites typed on at least one population sample and 288 populations typed for at least one polymorphism [11].

Website: http://alfred.med.yale.edu/alfred/index.asp

\section{The Tuberculosis Database}

Tuberculosis (TB) is a public health challenge of paramount importance. Control of TB will require a multifaceted approach integrating efficient public health interventions with the discovery and use of new vaccines and drugs. TBDatabase (TBDB) makes available the tools and resources available at the Stanford Microarray Database and the Broad Institute. 


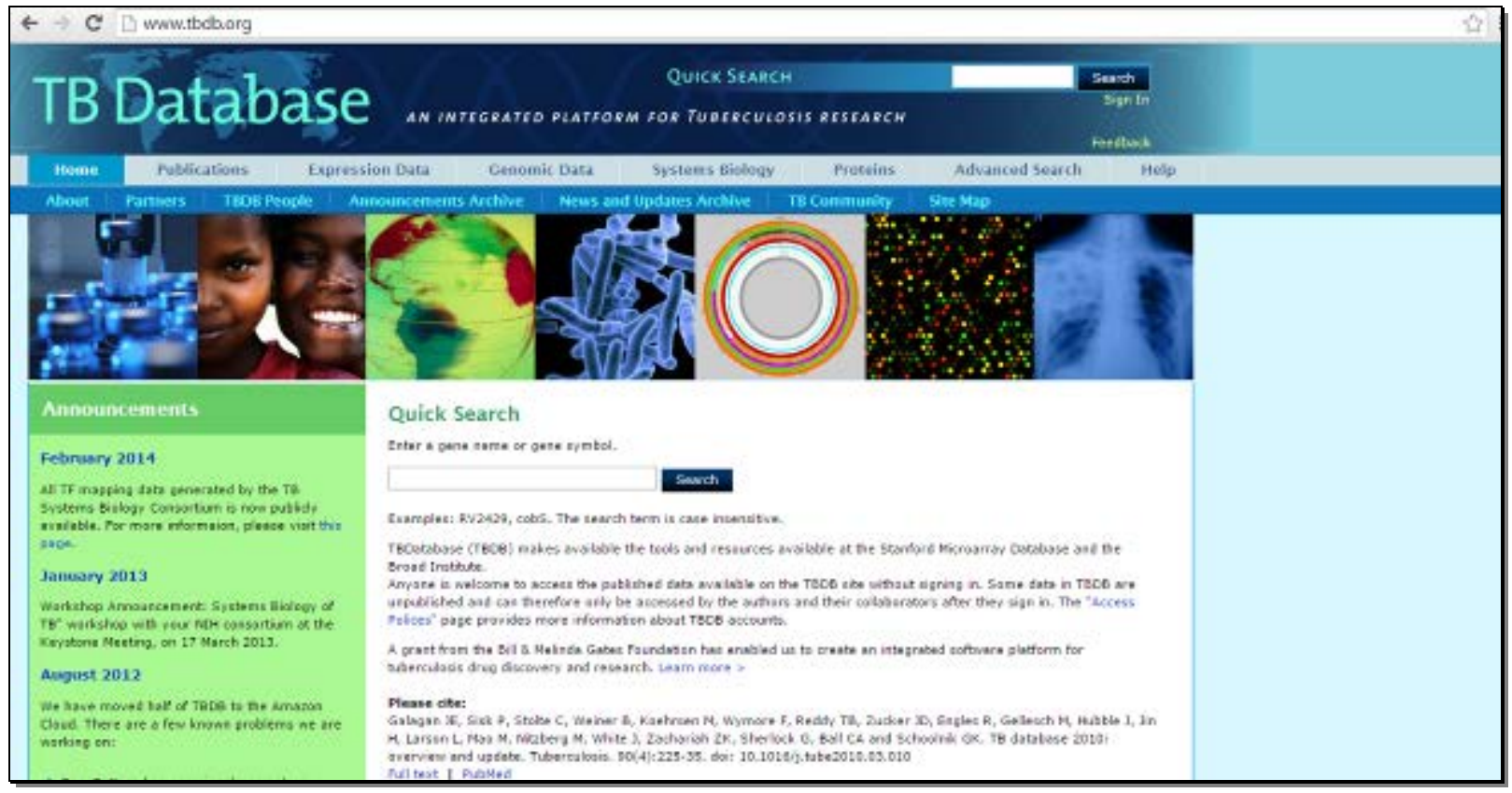

Figure 7: Home Page of Tuberculosis Database

Anyone is welcome to access the published data available on the TBDB site without signing in. Some data in TBDB are unpublished and can therefore only be accessed by the authors and their collaborators after they sign in. The "Access Polices" page provides more information about TBDB accounts [12].

Website: http://www.tbdb.org/

\section{The Genetic Association Databases}

The Genetic Association Database is an archive of human genetic association studies of complex diseases and disorders. This includes summary data extracted from published papers in peer reviewed journals on candidate gene and GWAS studies. 
OJPlin

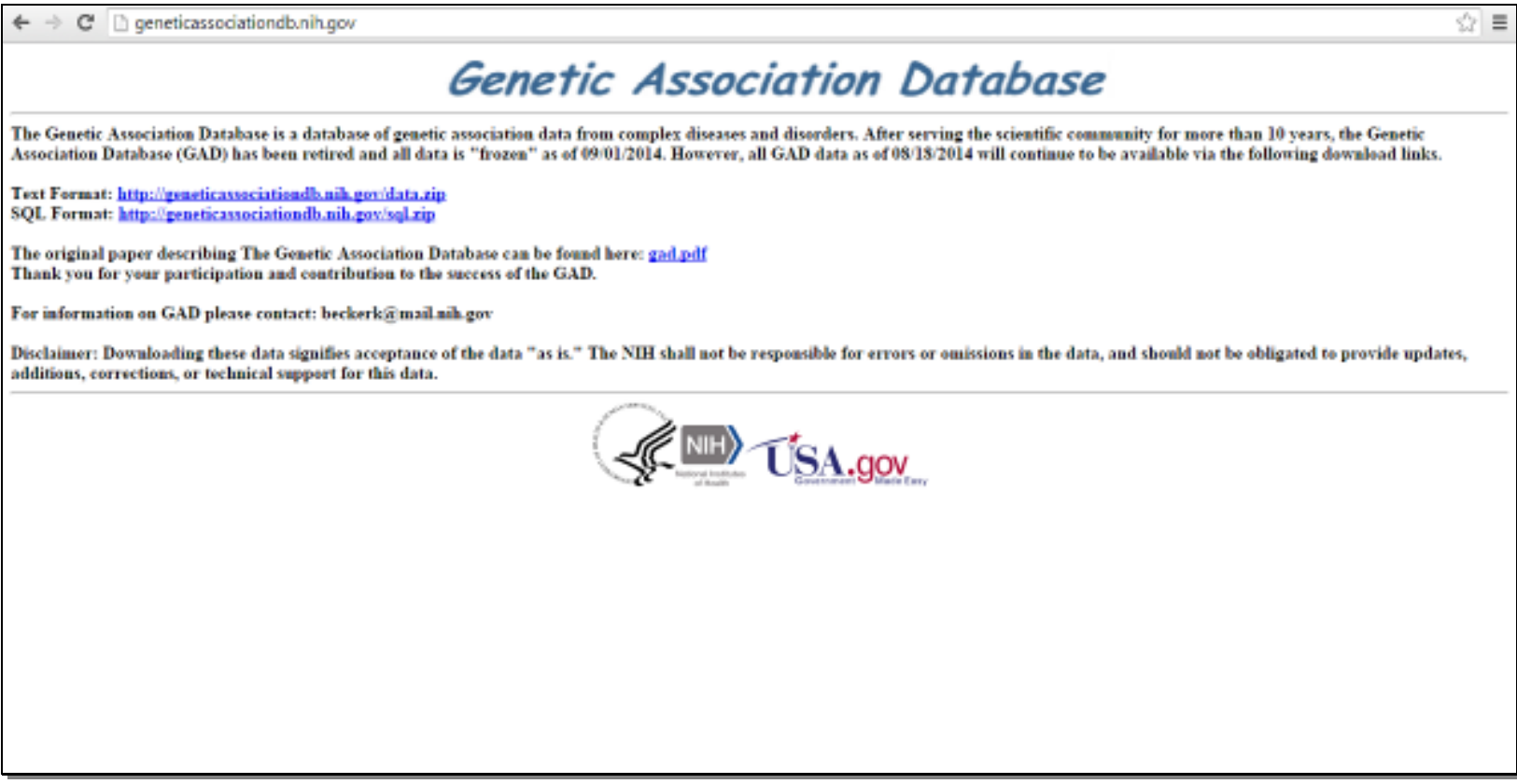

Figure 8: Home Page of Genetic Association Database

The goal of this database is to allow the user to rapidly identify medically relevant polymorphism from the large volume of polymorphism and mutational data, in the context of standardized nomenclature.

Study data are recorded in the context of official human gene nomenclature with additional molecular reference numbers and links. It is gene centered. That is, each record is a record of a gene or marker. If a study investigated 6 genes for a particular disorder, there will be 6 records.

The best feature of it that anyone may view this database, and anyone may submit records [13]. Website: http://geneticassociationdb.nih.gov/

\section{OMIM ${ }^{\circledR}$ - Online Mendelian Inheritance in Man ${ }^{\circledR}$}

Welcome to $\mathrm{OMIM} \AA$, Online Mendelian Inheritance in Man ${ }^{\circledR}$. OMIM is a comprehensive, authoritative compendium of human genes and genetic phenotypes that is freely available and updated daily. The full-text, referenced overviews in OMIM contain information on all known Mendelian disorders and over 12,000 genes. OMIM focuses on the relationship between phenotype and genotype. It is updated daily, and the entries contain copious links to other genetics resources. 
$\leftarrow \rightarrow C \sqrt{D}$ www.omimorg

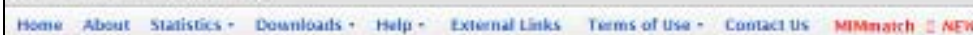

21) Selcet Languge

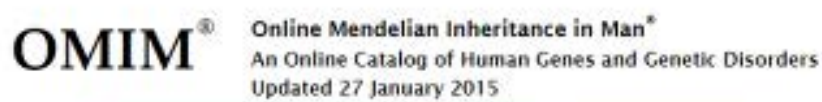

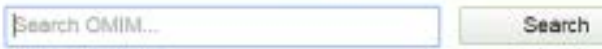

Advanced Search : ONim Clinical Synopses, Gene Mrp

Need help? i Example Searches, ONum Search Help. OMuM Tutorial

Nirrer sites : us-eastomin.erg, europe.omin.org

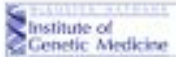

Figure 9: Home Page of OMIM

This database was initiated in the early 1960s by Dr. Victor A. McKusick as a catalog of Mendelian traits and disorders, entitled Mendelian Inheritance in Man (MIM). Twelve book editions of MIM were published between 1966 and 1998. The online version, OMIM, was created in 1985 by a collaboration between the National Library of Medicine and the William H. Welch Medical Library at Johns Hopkins. It was made generally available on the internet starting in 1987. In 1995, OMIM was developed for the World Wide Web by NCBI, the National Center for Biotechnology Information [14].

Website: http://www.omim.org/

\section{GeneCards ${ }^{\circledR}$}

GeneCards is a searchable, integrated database of human genes that provides comprehensive, updated, and user-friendly information on all known and predicted human genes. 


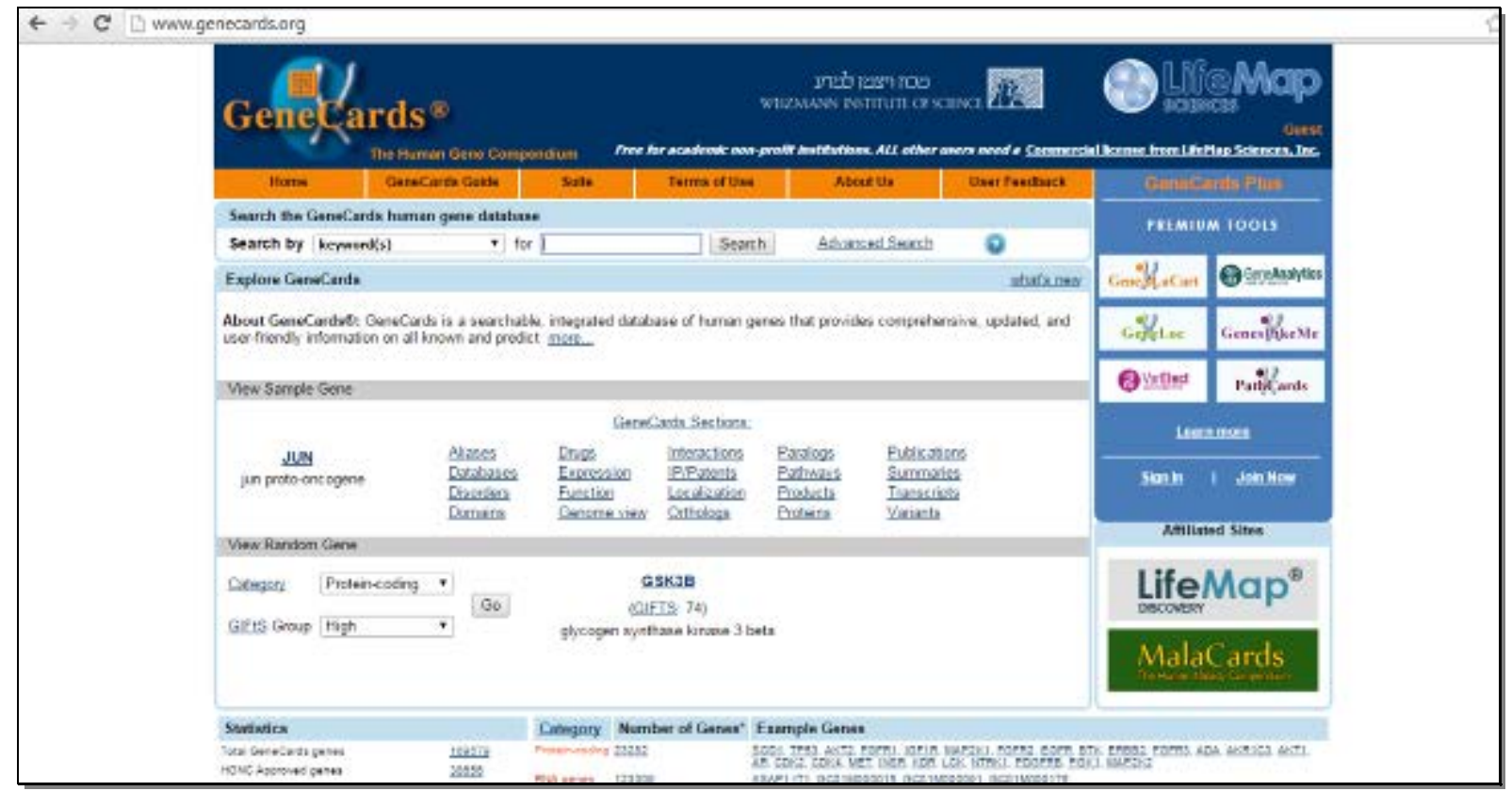

Figure 10: Home Page of GeneCards

GeneCards extracts and integrates gene-related data, including genomic, transcriptomic, proteomic, genetic, clinical, and functional information. This is automatically mined from $>100$ carefully selected web sources, thereby allowing one-stop access to a very broad information base. GeneCards overcomes barriers of data format and heterogeneity, and uses standard nomenclature and approved gene symbols. It presents a rich subset of data for each gene, and provides deep links to the original sources for further scrutiny. GeneCards is widely used, and assists in the understanding of gene-related aspects of biology and medicine [15].

Website: http://www.genecards.org/

\section{ClinVar}

ClinVar provides a freely accessible, public archive of reports of the relationships among human variations and phenotypes, with supporting evidence. 


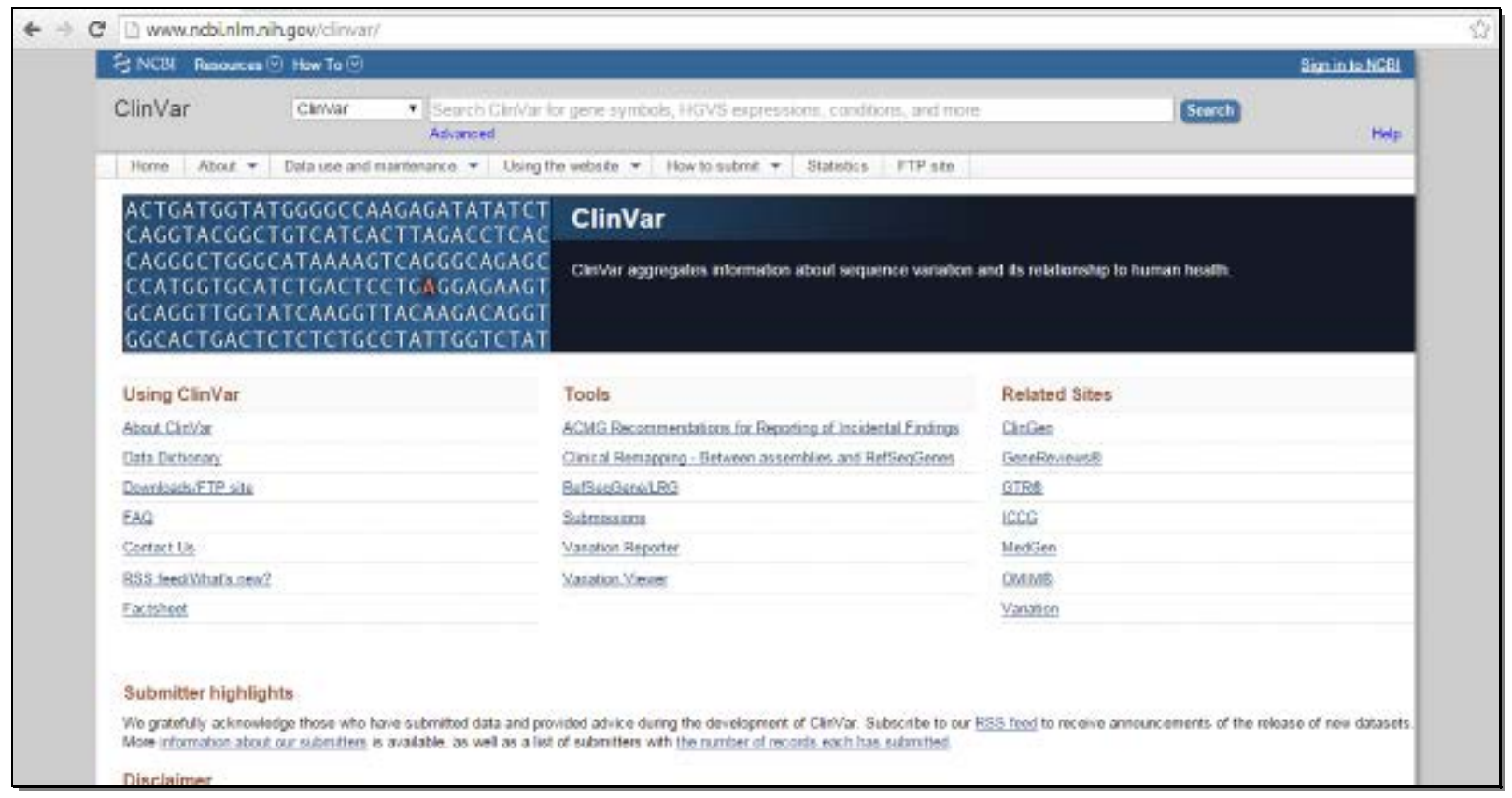

Figure 11: Home Page of ClinVar

ClinVar facilitates access to and communication about the relationships asserted between human variation and observed health status, and the history of that interpretation. ClinVar collects reports of variants found in patient samples, assertions made regarding their clinical significance, information about the submitter, and other supporting data. The alleles described in submissions are mapped to reference sequences, and reported according to the HGVS standard. ClinVar then presents the data for interactive users as well as those wishing to use ClinVar in daily workflows and other local applications. ClinVar works in collaboration with interested organizations to meet the needs of the medical genetics community as efficiently and effectively as possible [16].

Website: http://www.ncbi.nlm.nih.gov/clinvar/

\section{Medical Subject Headings (MeSH $\left.{ }^{\circledR}\right)$}

MeSH is the National Library of Medicine's controlled vocabulary thesaurus. It consists of sets of terms naming descriptors in a hierarchical structure that permits searching at various levels of specificity. 


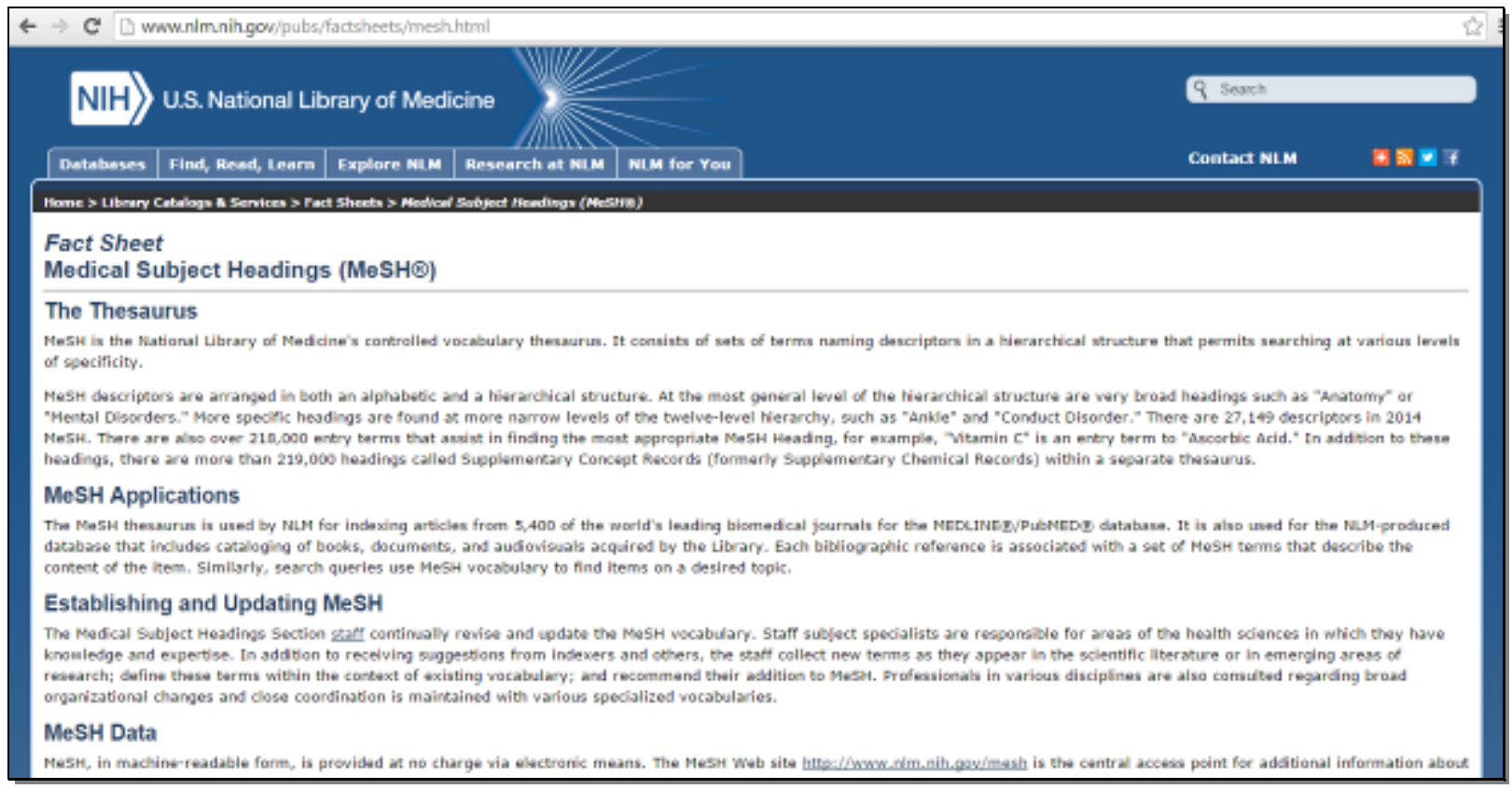

Figure 12: Home Page of MeSH

$\mathrm{MeSH}$ descriptors are arranged in both an alphabetic and a hierarchical structure. At the most general levels of the hierarchical structure are very broad headings such as "Anatomy" or "Mental Disorders." More specific headings are found at more narrow levels of the twelve-level hierarchy, such as "Ankle" and "Conduct Disorder." There are 27,149 descriptors in 2014 MeSH. There are also over 218,000 entry terms that assist in finding the most appropriate MeSH Heading, for example, "Vitamin C" is an entry term to "Ascorbic Acid." In addition to these headings, there are more than 219,000 headings called Supplementary Concept Records (formerly Supplementary Chemical Records) within a separate thesaurus.

\section{MeSH Applications}

The MeSH thesaurus is used by NLM for indexing articles from 5,400 of the world's leading biomedical journals for the MEDLINE®/PubMED® database. It is also used for the NLMproduced database that includes cataloging of books, documents, and audiovisuals acquired by the Library. Each bibliographic reference is associated with a set of MeSH terms that describe the content of the item. Similarly, search queries use MeSH vocabulary to find items on a desired topic [17].

Website: http://www.nlm.nih.gov/pubs/factsheets/mesh.html

\section{Global Atlas of Infectious Diseases}

In a single electronic platform, the WHO's Communicable Disease Global Atlas is bringing together for analysis and comparison standardized data and statistics for infectious diseases at country, regional, and global levels. The analysis and interpretation of data are further supported through information on demography, socioeconomic conditions, and environmental factors. In so 
doing, the Atlas specifically acknowledges the broad range of determinants that influence patterns of infectious disease transmission.

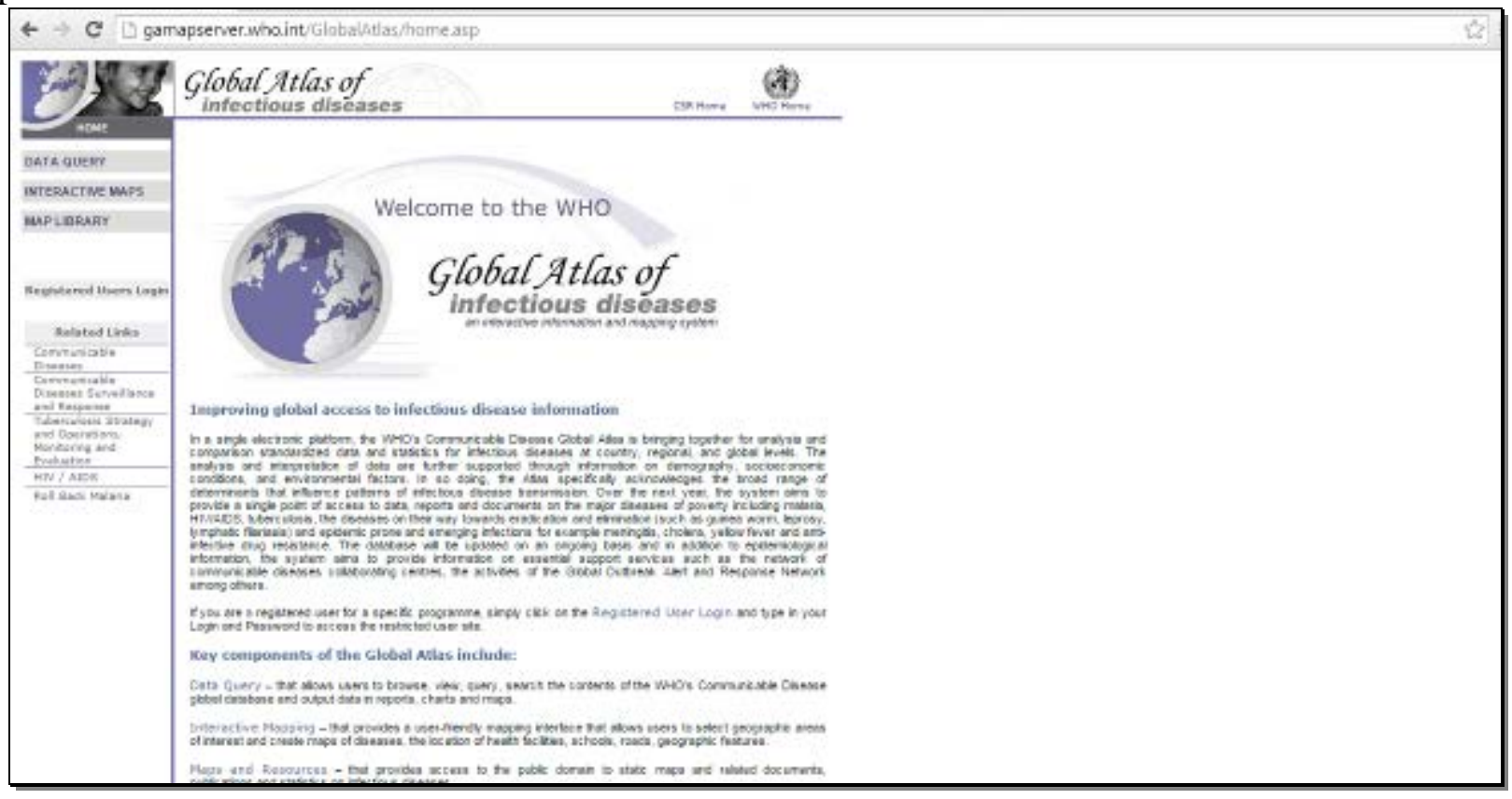

Figure 13: Home Page of Global Atlas of Infectious Diseases

Over the next year, the system aims to provide a single point of access to data, reports and documents on the major diseases of poverty, including malaria, HIV/AIDS, tuberculosis, the diseases on their way towards eradication and elimination (such as guinea worm, leprosy, lymphatic filariasis) and epidemic prone and emerging infections for example meningitis, cholera, yellow fever and anti-infective drug resistance. The database will be updated on an ongoing basis and in addition to epidemiological information, the system aims to provide information on essential support services such as the network of communicable diseases collaborating centers, the activities of the Global Outbreak Alert and Response Network among others.

Website http://gamapserver.who.int/GlobalAtlas/home.asp

\section{Cell Centered Database ${ }^{T M}$}

The CCDB project was started in 1998 under the auspices of the Human Brain Project to provide a venue for sharing and mining, cellular and sub cellular data derived from light and electron microscopy, including correlated imaging. It was one of the first web databases devoted to the then emerging technique of electron tomography $[18,19]$. 


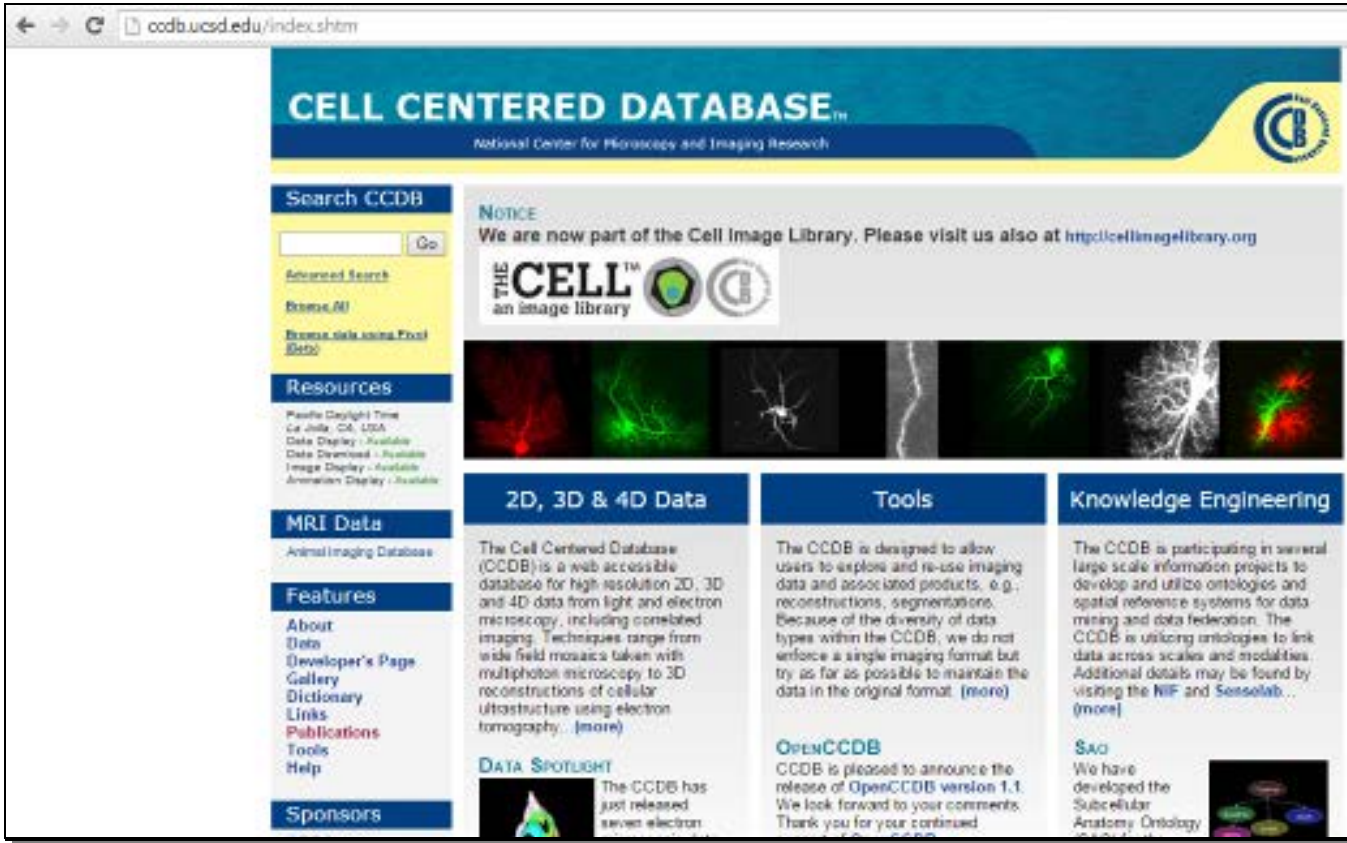

Figure 14: Home Page of CCDB

The CCDB has been on-line since 2002. The goals of the CCDB project include:

- Providing access for the biomedical community to primary and derived imaging, 2D, 3D and 4D data from light and electron microscopy

- Developing advanced database capabilities for storing and mining complex cellular and subcellular imaging data

- Creating the necessary infrastructure for managing and sharing light and electron microscopic data securely within and between laboratories

- Developing tools and strategies for integrating data across scales and modalities and federating databases through the use of ontologies and shared spatial frameworks.

Website: http://ccdb.ucsd.edu/index.shtm

\section{The Human Protein Atlas}

The Human Protein Atlas portal is a publicly available database with millions of high-resolution images showing the spatial distribution of proteins in 44 different normal human tissues and 20 different cancer types, as well as 46 different human cell lines. 


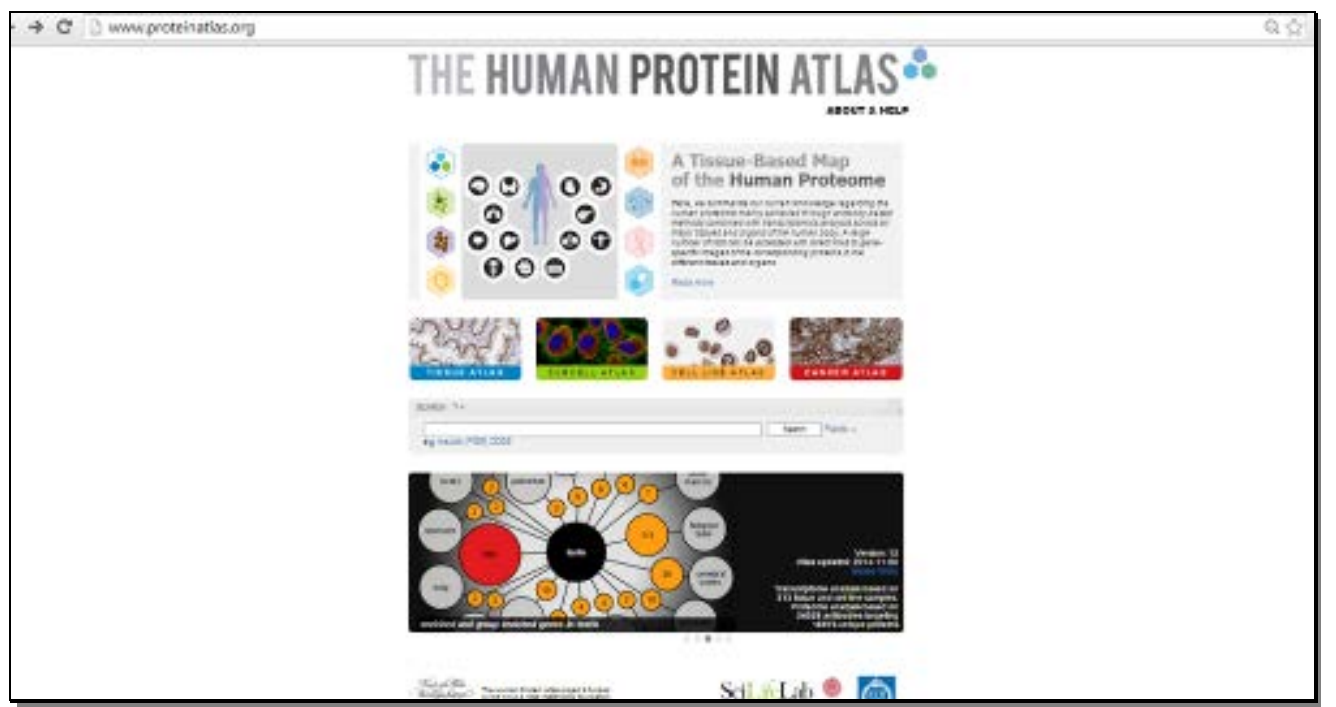

Figure 15: Home Page of The Human Protein Atlas

The data are released together with application-specific validation performed for each antibody, including immunohistochemisty, Western blot analysis and, for a large fraction, a protein array assay and immunofluorescent based confocal microscopy. The database has been developed in a gene-centric manner with the inclusion of all human genes predicted from genome efforts. Search functionalities allow for complex queries regarding protein expression profiles, protein classes and chromosome location [20].

Website: http://www.proteinatlas.org/ 


\section{National Information Center on Health Services Research and Health Care Technology (NICHSR)}

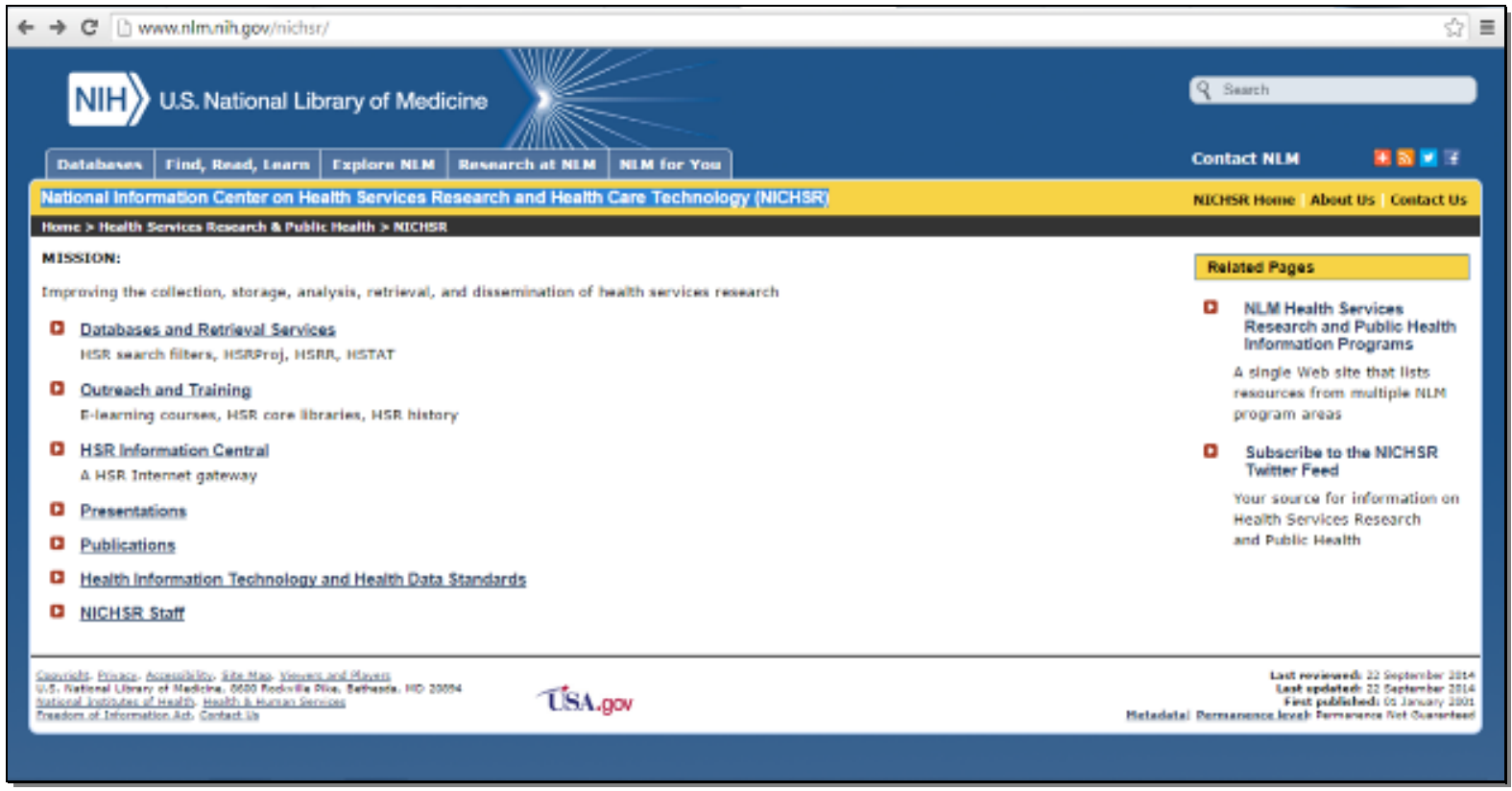

Figure 16: Home Page of NICHSR

The overall goals of the NICHSR are: to make the results of health services research, including practice guidelines and technology assessments, readily available to health practitioners, health care administrators, health policy makers, payers, and the information professionals who serve these groups; to improve access to data and information needed by the creators of health services research; and to contribute to the information infrastructure needed to foster patient record systems that can produce useful health services research data as a by-product of providing health care.

Website: http://www.nlm.nih.gov/nichsr/

\section{CDC WONDER}

Welcome to CDC WONDER -- Wide-ranging Online Data for Epidemiologic Research -- an easy-to-use, menu-driven system that makes the information resources of the Centers for Disease Control and Prevention (CDC) available to public health professionals and the public at large. It provides access to a wide array of public health information. 


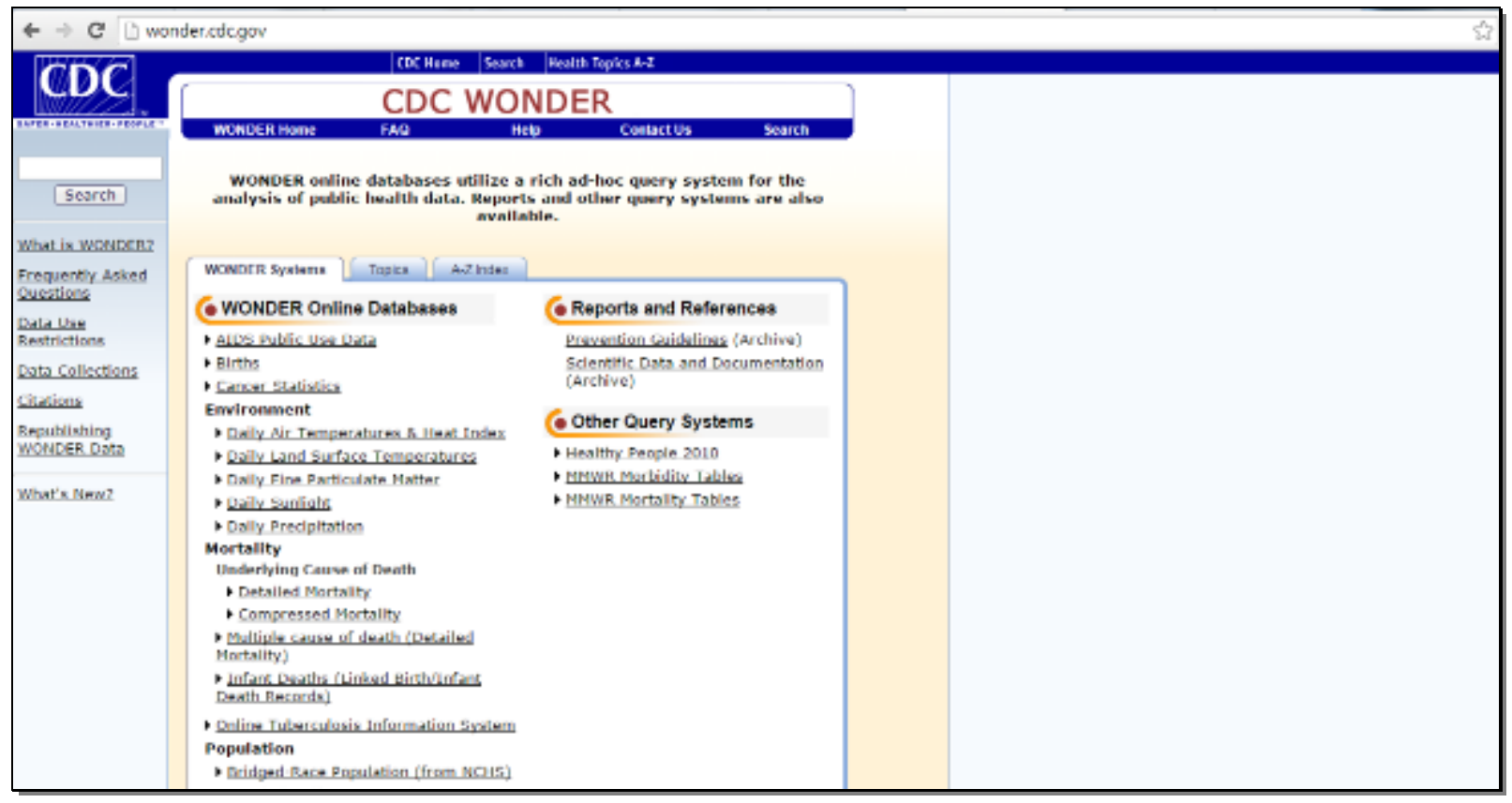

Figure 17: Home Page of CDC WONDER

With CDC WONDER you can:

- Access statistical research data published by CDC, as well as reference materials, reports and guidelines on health-related topics;

- Query numeric data sets on CDC's computers, via "fill-in-the blank" web pages. Public-use data sets about mortality (deaths), cancer incidence, HIV and AIDS, tuberculosis, vaccinations, natality (births), census data and many other topics are available for query, and the requested data are readily summarized and analyzed, with dynamically calculated statistics, charts and maps.

Website: http://wonder.cdc.gov/

\section{The Incidence and Prevalence Database (IPD)}

The Incidence and Prevalence Database (IPD) is the most efficient way to look at the world's epidemiology data. The IPD covers over 4,500 diseases, procedures, symptoms and other health issues for incidence, prevalence, morbidity, mortality, comorbidity, treated or diagnosed rates, cost and much more. 


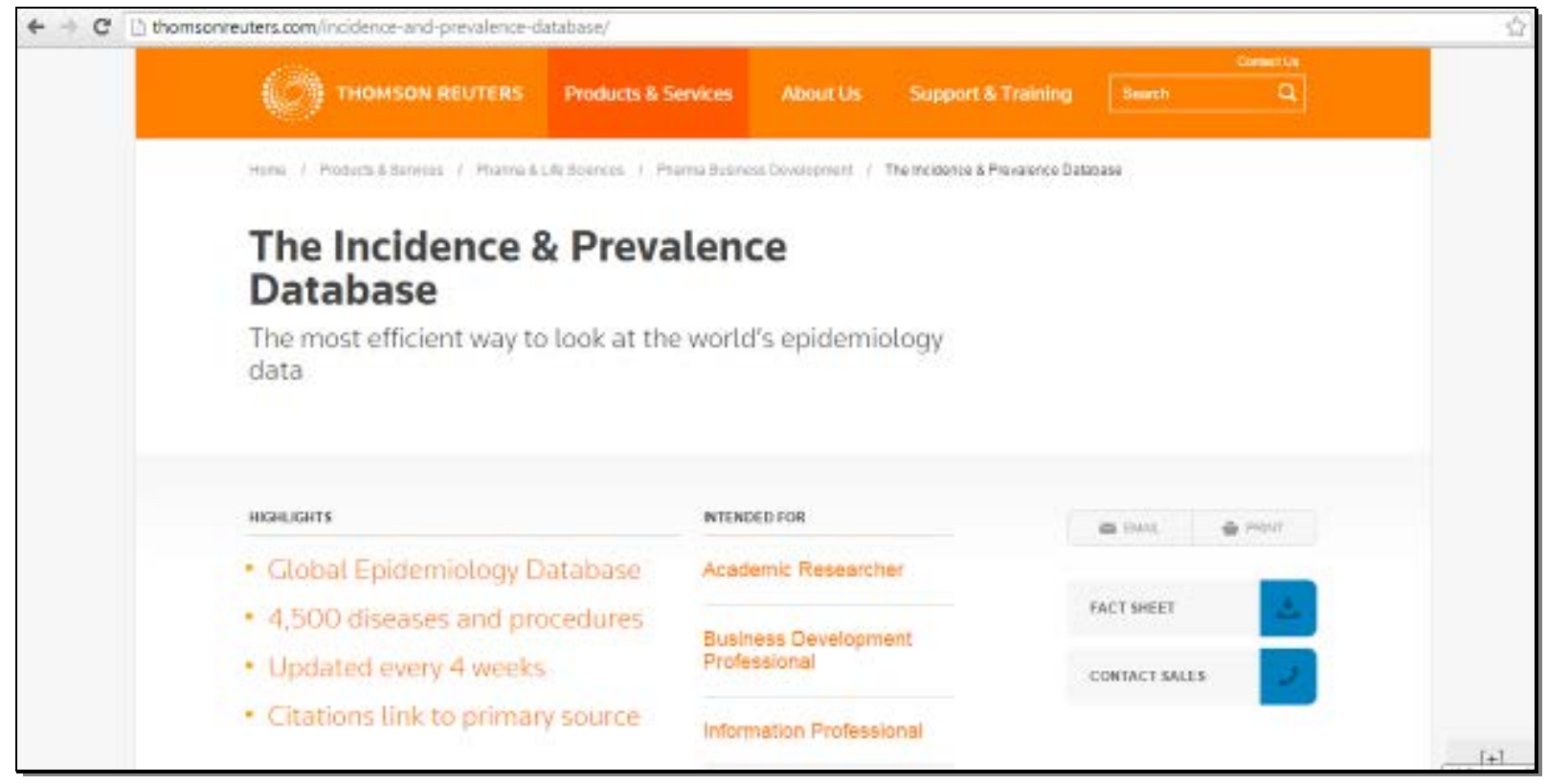

Figure 18: Home Page of IPD

Our analysts track and report the epidemiological content for more than 280 medical journals and over 35 government and industry agencies. The global reach of the IPD includes all countries and regions where data are available.

IPD combines extensive epidemiological and market research experience with the breadth of Life Sciences service offerings from Thomson Reuters, creating a powerful combination for clients.

Website http://thomsonreuters.com/incidence-and-prevalence-database/ 


\section{ALZRISK AD EPIDEMIOLOGY DATABASE}

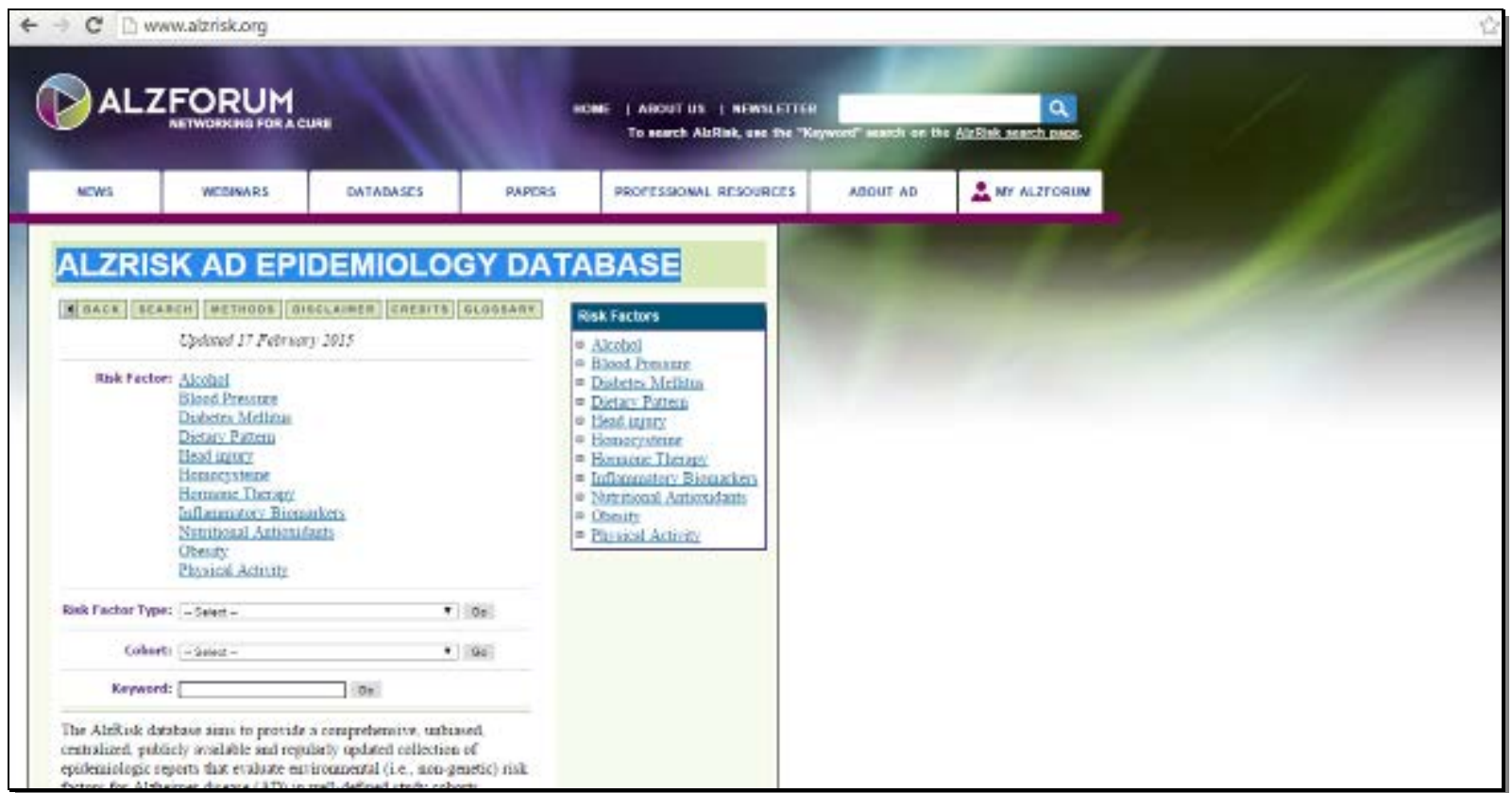

Figure 19: Home Page of ALZRISK AD EPIDEMIOLOGY DATABASE

The AlzRisk database aims to provide a comprehensive, unbiased, centralized, publicly available and regularly updated collection of epidemiologic reports that evaluate environmental (i.e., nongenetic) risk factors for Alzheimer disease (AD) in well-defined study cohorts. Eligible publications are identified through contact with each cohort study supplemented by a systematic review of the literature [21].

Website http://www.alzrisk.org/

\section{Atlas of MS}

The Atlas of MS is the most extensive worldwide study of the disease. 


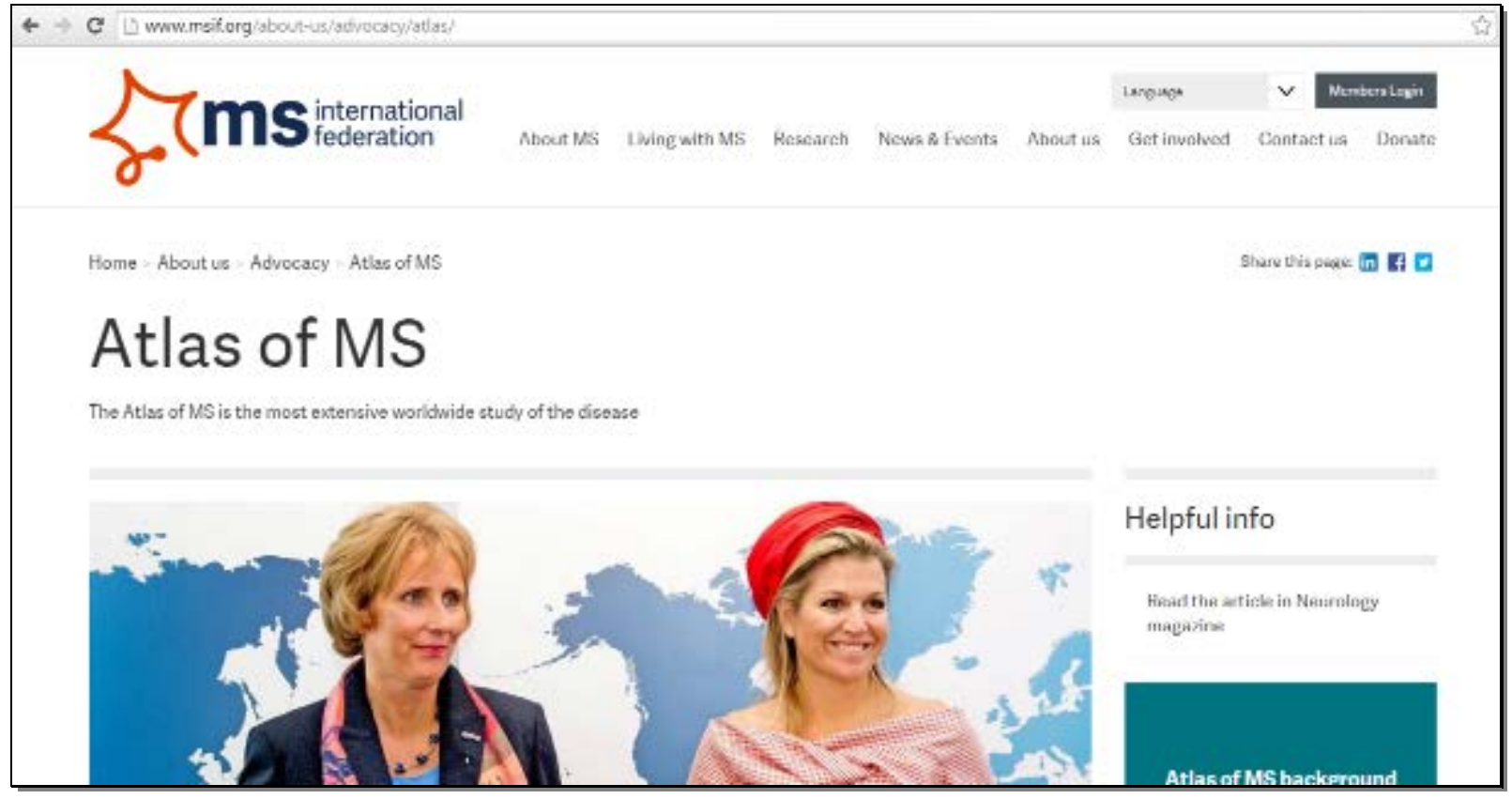

Figure 20: Home Page of Atlas MS

The Atlas of MS is the most extensive worldwide study of the epidemiology of MS and the global availability and accessibility of resources for people with MS.

In September 2008, the MS International Federation and the World Health Organization (WHO) published Atlas: Multiple Sclerosis Resources in the World 2008.

As well as the published report, the MS International Federation developed the first Atlas of MS website, which enabled users to query the data online, and to compare results across different regions and countries.

In 2012/2013 the MS International Federation carried out a second survey in order to update the information in the Atlas and the 2013 data was added to the 2008 information online.

Website http://www.msif.org/about-us/advocacy/atlas/

\section{Conclusion}

In this era of technology, the information technology is playing a vital role in different spheres of human life. Human lives are benefitted with the emergence of information technology by making the use of online available information related to disease, its signs, symptoms, precautionary measures and available contact information of the experts those can provide assistance when needed. Furthermore, it has become very easy for the human beings to develop an understanding about their biological system, seasonal diseases their home based treatments and precautions, food and nutrition, etc. Some of the databases and online resources are freely available for the retrieval of the information as discussed in the review. The emergence of robotic surgery, telemedicine, hospital information system, a centralized information system of the hospitals at the district level and state level as well demands the inclusion of biological and epidemiological databases in the medical course curriculum for the enhancement of public health education. But 
the major drawback is that it's not included in our education syllabus at the larger level. All the informatics resources have huge utilization at the academic level as well as research level. We can put the information about online public health and epidemiological databases in the syllabus which can definitely prove as strong asset for the public health education. Now we can decide our self why these databases should not be included in the medical course curriculum. Therefore, it is a need of an hour to fill the gap between the information technology and current public health education in order to utilize the online available resources at its best and serve the entire mankind.

\section{Acknowledgments}

We would like to thank the all database curators for the development of informative portals to provide benefits to the scientific community. The reviews cannot be completed without them.

\section{Conflicts of Interest}

The authors declare no conflicts of interest.

\section{References}

1. MidContinental Region News. PubMed and MedlinePlus updates [Internet] National Network of Libraries of Medicine [rev 17 Aug 2009; cited 28 Mar 2011.

2. Kraft M. PubMed Health. The krafty librarian [Internet] [rev 19 Aug 2010; cited 28 Mar 2011].

3. Dettmar N. Who's on first? NLM and Google health searches. EagleDawg [Internet] [rev 9 Feb 2011; cited 28 Mar 2011].

4. Hamilton J. PubMed Health who? Psychology Today [Internet] [rev 14 Feb 2011; cited 28 Mar 2011].

5. National Center for Biotechnology Information (NCBI) New PubMed Health! @NCBI, Twitter.com [Internet] 2 Mar 2011 [cited 28 Mar 2011].

6. National Library of Medicine. PubMed Health about page [Internet] The Library [cited 4 Apr 2011].

7. Venuti J, Imielinska C, Laino-Pepper L, Thumann R, Molholt P. (6 October 2000). The Third Visible Human Project Conference Proceedings.

8. "Unified Medical Language System ${ }^{\circledR}(U M L S \circledR)$ News: Revised License Agreement, New UMLS Terminology Services and Browser, Discontinued UMLSKS, and API Changes". NLM Technical Bulletin. U.S. National Library of Medicine. 29 July 2010.

9. Rodney Long L, Stanley R. 1997. Pillemer; Reva C. Lawrence; Gin-Hua Goh; Leif Neve; George R. Thoma; WebMIRS: web-based medical information retrieval system. Proc. SPIE 3312. Storage and Retrieval for Image and Video Databases. VI, 392. doi:10.1117/12.298448.

10. National Library of Medicine Taps A.D.A.M. Multimedia Encyclopedia". Wireless News (Close-Up Media). April 1, 2009. 
11. Rajeevan H, Osier MV, Cheung KH, Deng H, Druskin L, et al. 2003. ALFRED - the ALlele FREquency Database - update. Nucleic Acids Res. 31(1), 270-71. http://dx.doi.org/10.1093/nar/gkg043.

12. Reddy TB, Riley R, Wymore F, Montgomery P, Decaprio D, et al. TB database: an integrated platform for tuberculosis research. Nucleic Acids Res. doi:10.1093/nar/gkn652.

13. Kevin G. 2004. Becker, Kathleen C Barnes, Tiffani J Bright \& S Alex Wang,The Genetic Association Database. Nat Genet. 36, 431-32. doi:10.1038/ng0504-431.

14. Hamosh A, Scott AF, Amberger JS, Bocchini CA, McKusick VA. 2004. Online Mendelian Inheritance in Man (OMIM), a knowledgebase of human genes and genetic disorders. Nucleic Acids Res. 33(Database issue), D514-17. http://dx.doi.org/10.1093/nar/gki033.

15. Rebhan M, Chalifa-Caspi V, Prilusky J. 1997. Lancet, D. GeneCards: integrating information about genes, proteins and diseases. Trends Genet. 13, 163. http://dx.doi.org/10.1016/S0168-9525(97)01103-7.

16. Landrum MJ, Lee JM, Riley GR, Jang W, Rubinstein WS, et al. 2014. ClinVar: public archive of relationships among sequence variation and human phenotype. Nucleic Acids Res. 42(1), D980-85. doi:http://dx.doi.org/10.1093/nar/gkt1113.

17. Rogers FB. (Jan 1963). "Medical subject headings". Bull Med Libr Assoc (in eng) 51: 1146. ISSN 0025-7338. PMC 197951. PMID 13982385.

18. Martone ME, Gupta A, Qian X, Wong M, Zhang S, et al. (2002). The cell centered database: An online resource for high resolution cell level data, Soc for Neurosci Abstr.

19. Martone ME, Gupta A, Wong M, Qian X, Sosinsky G, et al. 2002. A cell centered database for electron tomographic data. J Struct Biol. 138, 145-55.http://dx.doi.org/10.1016/S10478477(02)00006-0.

20. Uhlen, et al. 2010. Towards a knowledge-based Human Protein Atlas. Nat Biotechnol. 28(12), 1248-50. doi:http://dx.doi.org/10.1038/nbt1210-1248.

21. Weuve J, McQueen MB, Blacker D. The AlzRisk Database. Alzheimer Research Forum. Available at: http://www.alzforum.org. Accessed [date of access]*. 